\title{
BORGES, LEIBNIZ Y LA METAFÍSICA DE LOS ESPEJOS*
}

\author{
BORGES, LEIBNIZ AND THE MetaPHySiCS Of MirRorS \\ GRISELDA GAIADA \\ NATIONAL UNIVERSITY OF LA PLATA
}

\begin{abstract}
Resumen
Escéptico por vocación, Borges defendió, pese al vasto reservorio filosófico que animó su obra, una concepción de la metafísica singularmente provocativa: la metafísica no es más que una rama de la literatura fantástica. A partir de esta fórmula, que prima facie parece invalidar a aquélla en sus pretensiones epistémicas, abordaremos ciertas conexiones entre las letras de Borges y las de Leibniz con relación a lo que llamaremos una 'metafísica de los espejos'. Borges invocará a menudo el nombre de Leibniz y llevará a cabo la 'realización literaria' de un conjunto de tesis especialmente caras al filósofo. Aunque distantes en tiempo y lugar, un 'diálogo' parece producirse entre ambos en el cenáculo de una tradición común.
\end{abstract}

\section{Palabras-clave}

Borges, Leibniz, metafísica, Dios, expresión universal.

\section{Abstract}

Sceptical by vocation, Borges defended, despite the vast philosophical reservoir that animated his work, a singularly provocative conception of metaphysics: it is only a branch of the literature of fantasy. From this sentence, which prima facie seems to invalidate metaphysics in its epistemic pretensions, we will address some connections between Borges's and Leibniz's letters in relation to what we will call a 'metaphysics of mirrors'. Borges will often invoke the name of Leibniz and give 'literary form' to a set of theses being at the core of Leibnizian metaphysics. Although distant in time and space, it seems that a 'dialogue' takes place between both of them in the cenacle of a common tradition.

\section{Key Words}

Borges, Leibniz, Metaphysics, God, Universal Expression.

\section{$\boldsymbol{\infty}$}

\footnotetext{
* Este artículo fue realizado en el marco de una beca de nivel superior de la Agencia Nacional de Promoción Científica y Tecnológica, obtenida por el proyecto de investigación: 'La metafísica modal leibniziana: necesidad y contingencia. Contradicciones y fisuras en el pensamiento de Leibniz'. Este último se inscribe dentro del PICT-2017-0506 (ANPCyT).
} 
Ich bin du, wenn ich ich bin. Lob der Ferne, Paul Celan

Como es sabido, Jorge Luis Borges (1899-1986) se sintió fuertemente atraído por la filosofía. Pese a ello, no fue un filósofo en el sentido habitual del término. No lo fue porque su literatura no constituyó un 'pretexto' para tomar partido por ciertas ideas o convicciones filosóficas, ni tampoco buscó dar fundamento racional a cierta comprensión del mundo. No obstante, lo fue a su manera y en un modo quizá más elevado, no sólo porque su comprensión de la filosofía ha superado con creces la de tantos filósofos de profesión, sino también, y sobre todo, porque se ha dejado inspirar por los grandes interrogantes y problemas que definen propiamente a la filosofía. ${ }^{1}$

Su obra fue en esencia una obra de la imaginación, es decir, destinada a expresar nociones de diversa índole mediante imágenes. ${ }^{2}$ Esto incluye versos, personajes y tramas ficticias, pero también una plétora de símbolos, entendidos como imágenes que sugieren o aluden algo que escapa al uso corriente del lenguaje humano. ${ }^{3}$ Si la riqueza abrumadora de su obra no sabría explicarse sin un caudal inmenso de temas metafísicos, Borges defendió, no obstante, una concepción de la metafísica singularmente provocativa, cuya formulación más famosa se encuentra en el cuento « Tlön, Uqbar, Orbis Tertius »:

El hecho de que toda filosofía sea de antemano un juego dialéctico, una Philosophie des Als Ob, ha contribuido a multiplicarlas. Abundan los sistemas increíbles, pero de arquitectura agradable o de tipo sensacional. Los metafísicos de Tlön no buscan la

1 Para las relaciones entre Borges y la filosofía, véanse por ejemplo: DiDIER T. JAÉN, Borges' Esoteric Library: Metaphysics to Metafiction, University Press of America, Lanham 1992; MARCIN KAZMIERCZAK, "La metafísica idealista en los relatos de Jorge Luis Borges », tesis doctoral, Universidad Autónoma de Barcelona, 2001, disponible online en: <https://www.tesisenred.net/ handle/10803/4860\#page=1> (consultado el 30 de diciembre de 2020); LISA BLOCK DE BEHAR, The Passion of an Endless Quotation, trans. by WiLLIAM EGGINTON, State University of New York Press, New York 2003; JuAn NuÑo, La filosofía en Borges, Reverso Ediciones, Barcelona 2005; MARCELO SAsso, Borges en clave de Elea, Teseo Press, Buenos Aires 2015.

${ }^{2}$ En « Nathaniel Hawthorne », Borges distingue entre el escritor que piensa por imágenes, en general los grandes hombres y mujeres de letras, y el que lo hace por abstracciones, cuyas letras, al pasar del ámbito 'razonador' al 'imaginativo', suelen malograrse. Véase JoRGE LUIS BORGES « Nathaniel Hawthorne », Otras inquisiciones, en Obras completas 1923-1972 (O. C.), Emecé, Buenos Aires 1974, p. 673.

3 Según Borges, los símbolos, si son realmente tales, formulan conexiones íntimas entre las cosas y han existido siempre; los que inventamos, en cambio, son precisamente los que no vale la pena inventar. Borges mismo ha caracterizado alguno de sus cuentos como simbolistas, tal es el caso de « La lotería en Babilonia ». Véase Jorge Luis Borges, Prólogo, Ficciones, O. C., p. 429. 
verdad ni siquiera la verosimilitud: buscan el asombro. Juzgan que la metafísica es una rama de la literatura fantástica. ${ }^{4}$

A esta apreciación, prima facie invalidante de la filosofía en sus aspiraciones metafísicas, se añaden otras expresiones del mismo tenor, como, por ejemplo, cuando en diálogo con Ernesto Sábato, afirmó que «Dios es la máxima creación de la literatura fantástica. Lo que imaginaron Wells, Kafka o Poe no es nada comparado con lo que imaginó la teología. La idea de un ser perfecto, omnipotente, todopoderoso es realmente fantástica $» .^{5}$ Esta patente ironía de Borges, en la que más de uno estaría tentado de ver un simple reflejo de su escepticismo, debería implicar, si en verdad es tal, alguna otra cosa que lo que se ha dicho. Quizá podría verse allí el hecho obvio de que toda metafísica o teología entraña una limitación, derivada de su carácter humano y suplida las más de las veces con la propia imaginación, para conducir a aquello que la rebasa y que paradójicamente se plantea como su legítimo objeto. Pero también podría verse allí otro aspecto de este hecho, a saber que, pese a su parcialidad y limitación, no dejan de aludir o sugerir algo que el lenguaje no alcanza, del mismo modo en que lo hace la literatura $\mathrm{y}$, singularmente, la poesía. ${ }^{6}$ Lo primero se liga más estrechamente a eso que se nos rehúye $u$ oculta; lo segundo a lo que se muestra o expone, si bien siempre de forma velada. Ni la literatura, ni la metafísica, ni la teología, escapan a la dialéctica mostración-ocultación, cuyo alcance parecería implicar también la naturaleza de algo más profundo.

La filosofía, al igual que la poesía, apuntaría según Borges a mostrar un más allá del lenguaje que, aunque se oculte, no por ello se expone menos en el más acá de las diversas filosofías producidas por el hombre. Aunque la 'realidad' como tal

4 Jorge Luis Borges, "Tlön, Uqbar, Orbis Tertius », Ficciones, O. C., p. 436. Nuestro resaltado. Posteriormente dirá en las « Notas" de Discusión: "Yo he compilado alguna vez una antología de la literatura fantástica. Admito que esa obra es de las poquísimas que un segundo Noé debería salvar de un segundo diluvio, pero delato la culpable omisión de los insospechados y mayores maestros del género: Parménides, Platón, Juan Escoto Erígena, Alberto Magno, Spinoza, Leibniz, Kant, Francis Bradley. En efecto, ¿qué son los prodigios de Wells o de Edgar Allan Poe - una flor que nos llega del porvenir, un muerto sometido a la hipnosis - confrontados con la invención de Dios, con la teoría laboriosa de un ser que de algún modo es tres y que solitariamente perdura fuera del tiempo? ¿Qué es la piedra bezoar ante la armonía preestablecida, quién es el unicornio ante la Trinidad, quién es Lucio Apuleyo ante los multiplicadores de Buddhas del Gran Vehículo, qué son todas las noches de Shahrazad junto a un argumento de Berkeley? » (JoRGE LuIs Borges, « Notas », Discusión, O. C., p. 280-281).

JoRge Luis Borges, ERnESTo SABATO, Diálogos, Emecé, Buenos Aires 1976, p. 75.

6 Estos dos aspectos de limitación y acercamiento al objeto son referidos por Borges como sigue: « Es aventurado pensar que una coordinación de palabras (otra cosa no son las filosofías) pueda parecerse mucho al universo. También es aventurado pensar que de esas coordinaciones ilustres, alguna - siquiera de modo infinitesimal - no se parezca un poco más que otras » (JORGE LUIS BORGES, « Avatares de la tortuga », Discusión, O.C., p. 258). 
Griselda Gaiada

se les escape e incluso la dejen ir en su voluntad de auto-justificarse, ${ }^{7}$ tales construcciones comportarían, para el escritor, una singular capacidad, la de poder situarnos ante la «inminencia de una revelación ». Este último término es clave en el registro hermenéutico de Borges: la revelación acecha, pero «no se produce ", nos dirá, o quizá se produce, pero no entendemos su decir, o lo hacemos, pero no podemos comunicarlo. ${ }^{8}$ Así pues, por su afán de multiplicarse en explicaciones omnímodas y por su ocasional virtud de "peinar lo real », los sistemas filosóficos abonan especialmente esta dimensión de espera, y hasta pueden devenir ocasión del hecho epifánico. Las referencias filosóficas de Borges son cuantiosas: Platón, Plotino, Averroes, Spinoza, Leibniz, Hegel, Schopenhauer, pero también, entre muchísimas otras, los remotos babilónicos, los primeros hebreos y hasta los desacreditados gnósticos. Cada una de ellas ameritaría sendos estudios de su 'realización' literaria en la obra borgeana. No es éste - ni podría serlo - nuestro propósito aquí. Por el contrario, tan sólo nos limitaremos a uno de los grandes filósofos que, de manera más o menos directa, más o menos oblicua, animó las letras del escritor argentino.

Asiduo lector de la Enciclopedia británica en su edición de 1911 - posiblemente, la ocasión de un primer encuentro con el pensamiento leibniziano-, Borges invocará con frecuencia el nombre de Gottfried W. Leibniz (1646-1716) y dará forma literaria a un conjunto de tesis singularmente caras al filósofo, derivadas de su principio de expresión, según el cual cualquier cosa del mundo puede entenderse como si fuera un espejo viviente de todo lo que existe. Nuestro objeto es, pues, mostrar las estrechas conexiones que pueden establecerse entre las letras de Borges y las de Leibniz en relación con lo que llamaremos una 'metafísica de los espejos'. Como veremos, la dialéctica mostración-ocultación, que caracterizaría el vínculo entre las Philosophien des Als ob y la onticidad inasimilable al Als Ob, estará en el centro de nuestro desarrollo, el cual, lejos de

7 Esta auto-justificación en la que suelen incurrir los filósofos encontrará también su expresión en «Los avatares de la tortuga »: «Admitamos lo que todos los idealistas admiten: el carácter alucinatorio del mundo [...] El mayor hechicero (escribe memorablemente Novalis) sería el que se hechizara hasta el punto de tomar sus propias fantasmagorías por apariciones autónomas. ¿No sería ése nuestro caso? Yo conjeturo que así es. Nosotros (la indivisa divinidad que opera en nosotros) hemos soñado el mundo. Lo hemos soñado resistente, misterioso, visible, ubicuo en el espacio y firme en el tiempo... » (BORGES, « Avatares de la tortuga », p. 258, nuestro resaltado).

8 El pasaje completo versa así: «La música, los estados de felicidad, la mitología, las caras trabajadas por el tiempo, ciertos crepúsculos y ciertos lugares, quieren decirnos algo, o algo dijeron que no hubiéramos debido perder, o están por decir algo; esta inminencia de una revelación que no se produce es, quizá, el hecho estético » (JORGE LUIS BORGES, « La muralla y los libros », Otras inquisiciones, O. C., p. 635). También: « Hay una hora de la tarde en que la llanura está por decir algo; nunca lo dice, o tal vez lo dice infinitamente y no lo entendemos, o lo entendemos pero es intraducible como una música » (JoRGE LuIS BORGES, « El fin », Ficciones, O. C., p. 521). 
ser exhaustivo, remitirá a ciertos relatos y poemas de Borges, cuya selección bien podría haber sido otra.

\section{El Zahir, el Aleph y la expresión universal}

Borges fue particularmente sensible a la idea de un Dios que es en cierto modo cada cosa del mundo; o más bien, cabría decir que tal sentido de lo teológico constituyó una de sus intuiciones fundamentales, si no la más fundamental. Sin embargo, esa íntima convicción no lo llevó a comprometerse con ninguna filosofía o teología particular; nada más lejos de un Borges partidario de cierto sistema de pensamiento. Múltiples razones podrían conjeturarse al respecto. Entre ellas cuentan, sin duda primero, el marcado escepticismo del que el escritor hizo gala, ${ }^{9}$ pero también las insalvables diferencias entre el 'modo de pensar' filosófico y el literario - del que las modalidades propias del 'lenguaje intelectual' y del 'lenguaje literario' son tan sólo su expresión más visible -, así como el carácter esencialmente analítico de la filosofía, al que se opone singularmente la extraordinaria capacidad sintética de las letras de Borges - quizá en ello resida su principal virtud como escritor y la razón de la exclusión del inasimilable género novelesco. Pero además de estas razones, podría arriesgarse otra más esencial: mientras que las filosofías que conocemos se remontan a un tiempo determinado y suelen ser la obra de un autor con cuyo nombre se las conoce, lo que hay de verdad en todas ellas se confunde, por así decirlo, con el origen de los tiempos.

Por tal razón, si Borges fue en cierto sentido filósofo, metafísico o teólogo, no pudo serlo en un modo escolar, canónico $u$ ortodoxo, sino a la manera en que, según sus propias palabras, «todo hombre culto es un teólogo ». ${ }^{10}$ Dicho de otro modo, si su obra tradujo algún aspecto o forma de la Divinidad, no lo hizo como 'concepción', ya sea filosófica, cosmogónica o teológica, porque ‘concebir' es aprehender, captar, conceptuar, en definitiva, apropiarse (concipio, capio, auffassen, saisir, etc.). Y si hay algo de lo que Borges parece haber dado sobradas cuentas es del carácter inconcebible, ergo conjetural, cuando no insensato, de toda concepción que tome semejante idea por objeto. Por este motivo, creemos, carece de sentido indagar su obra a la busca de una clasificación teológica que la resuelva, por ejemplo, en términos inmanentistas o emanantistas. Por ello mismo también, está fuera de nuestro propósito (y en el fondo de cualquier propósito razonable) determinar si el Dios borgeano responde a una concepción panteísta, ${ }^{11}$

9 Para un análisis del escepticismo filosófico en la literatura de Borges, véase: BeRnAt CASTANY PRADO, Que nada se sabe: el escepticismo en la obra de Jorge Luis Borges, Universidad de Alicante, Alicante 2012 (Cuadernos de América sin nombre, 31), especialmente el capítulo 3.

10 JORGE LUIS BORGES, " El enigma de Edward Fitzgerald », Otras inquisiciones, O. C., p. 688.

11 Abundan las referencias a diversas formas de panteísmo en la obra de Borges. Por ejemplo: « El panteísmo ha divulgado un tipo de frases en las que se declara que Dios es diversas cosas contradictorias o (mejor aún) misceláneas. Su prototipo es éste: 'El rito soy, la ofrenda soy, la 
como la de Spinoza ${ }^{12}$ o cierta tradición cabalística, ${ }^{13}$ o a una concepción emanantista, como la de Plotino ${ }^{14}$ o Leibniz. ${ }^{15}$ Cualquier respuesta al respecto no

libación de manteca soy, el fuego soy' (Bhagavadgita, IX, 16). Anterior, pero ambiguo, es el fragmento 67 de Heráclito: 'Dios es día y noche, invierno y verano, guerra y paz, hartura y hambre.' (...) Attar, persa del siglo XII, canta la dura peregrinación de los pájaros en busca de su rey, el Simurg; muchos perecen en los mares, pero los sobrevivientes descubren que ellos son el Simurg y que el Simurg es cada uno de ellos y todos. Las posibilidades retóricas de esa extensión del principio de identidad parecen infinitas » (JORGE LuIS BORGES, « Nota sobre Walt Whitman », Discusión, O. C., p. 251). También: «Esa conjetura feliz afirma que hay un solo sujeto, que ese sujeto indivisible es cada uno de los seres del universo y que éstos son los órganos y máscaras de la divinidad» (BORGES, «Tlön, Uqbar, Orbis Tertius », p. 438). O como último ejemplo: « Mucho antes, el persa Umar Khyyam había escrito que la historia del mundo es una representación que Dios, el numeroso Dios de los panteístas, planea, representa y contempla, para distraer su eternidad » (BORGES, « Nathaniel Hawthorne », p. 670).

12 Son notorias las recurrentes referencias de Borges a la figura de Spinoza a lo largo de su obra. La fascinación de Borges por Spinoza probablemente pueda compararse, por su ambivalencia, a la que Leibniz mismo sintiera por aquél (para este tema, véase URSULA GOLDENBAUM, « La fascinación de Leibniz por Spinoza", en Leticia CABAÑAS, Oscar Esquisabel (eds.), Leibniz frente a Spinoza, Comares, Granada 2014, p. 31-50). Borges no sólo le dedicó los poemas que se encuentran en $E l$ otro, el mismo (« Spinoza ») y en La moneda de hierro (« Baruch Spinoza »), sino también algunas de sus conferencias («Baruch Spinoza», conferencia dictada el 22 de febrero de 1981 en la Escuela Freudiana de Buenos Aires; "Spinoza, el labrador de infinitos", conferencia pronunciada el 1 de abril de 1985 en la Sociedad Hebraica Argentina de Buenos Aires). Además, Spinoza aparece a menudo como una referencia impostergable en sus conversaciones y entrevistas, como es el caso de los célebres diálogos que el escritor mantuvo con Osvaldo Ferrari en sus últimos años de vida o de la entrevista que en 1974 dio a Jorge Ruffinelli en México. Pero quizá lo más curioso de su relación con Spinoza no sea, como suele pensarse, su confesión de no haberlo entendido, pese a haberle consagrado incontables pasajes de su obra, sino el hecho de que, en una irónica autobiografía, Borges se atribuyera como única autoría la composición de una obra titulada Clave de Baruch Spinoza que jamás escribió (JoRGE LUIS BoRGES, « Epílogo », O. C., p. 1143).

13 Con respecto a las relaciones establecidas por Borges entre la cábala y la filosofía de Spinoza, véanse sus notas a Die Elemente der Kabbalah (1913) de Erich Bischoff y a la Storia della filosofia (1918-1948) de Guido de Ruggiero, en LAURA Rosato, GERMÁn ÁLVAREZ (eds.), Borges, libros y lecturas. Catálogo de la colección Jorge Luis Borges en la Biblioteca Nacional, Biblioteca Nacional, Buenos Aires 2010 , p. 56. Entre la vasta literatura que ha estudiado la influencia de las fuentes cabalísticas en la obra de Borges, cabe destacar los siguientes títulos: ALBERT DeVRAn, Borges et la Kabbale, Edition Géranium, Bruselas 1967; SAÚl SosNowSKI, «Borges y la Cábala: La búsqueda del Verbo », Nuevos Aires, 8 (1972), p. 39-48; EDNA AIzENBERG, The Aleph Weaver: Biblical, Kabbalistic and Judaic Elements in Borges, Scripta Humanistica, Potomac (Maryland) 1984; JAIme AlazRaKi, Borges and the Kabbalah, and Other Essays on His Fiction and Poetry, Cambridge University Press, Cambridge 1988; ELLIoT R. Wolfson, « In the Mirror of the Dream: Borges and the Poetics of Kabbalah », The Jewish Quarterly Review, 104/3 (2014), p. 362-379.

14 La figura y el pensamiento de Plotino han atraído especialmente la atención de Borges. No sólo las Enéadas son el eje estructurante de la primera parte de su ensayo " Historia de la eternidad », sino que, más allá de la cuestión del tiempo, Borges remite al «Platón egipcio » en diversos contextos de contenido filosófico, constituyendo una referencia ineludible para la cuestión del panteísmo. 
podría no ser aventurada, además de falsear la profunda convicción del escritor de no plegarse a escuela o doctrina particular.

Pese a su escepticismo respecto de toda concepción filosófica particular, Borges creyó en el poder evocador que comparten la poesía y la filosofía por el hecho de que en ellas, de un modo especial, 'algo' se expone y se oculta a la vez. Este rasgo dialéctico, que la inteligencia filosófica de Borges captó como nadie para darle forma literaria, no sólo tiene profundas raíces metafísicas, sino también una larga historia que no es momento de recordar ahora. Tal vez allí, en esa intuición humana fundamental, anide el concepto mismo de 'expresión', del que Leibniz echó mano casi abusivamente y las más de las veces sin preocuparse por explicitar su significado. ${ }^{16}$

Concepto clave por su ubicuidad y por sus vastas consecuencias especulativas, la expresión implica también, aunque no sólo ello, exposición y ocultamiento. Dicho de otro modo, la expresión no es una mera relación especular entre las cosas, el mundo y Dios, sino una conexión más profunda, un nexo ontológico, que supone ante todo exposición, transformación, permanencia y ocultación. Muy sintéticamente, diremos que lo expresado se manifiesta en lo expresante y al hacerlo se hace otro en éste, pero permanece en él, aunque no en cuanto tal, sino bajo cierto aspecto particular que lo expone parcialmente ${ }^{17} \mathrm{y}$, por ende, también lo oculta. ${ }^{18}$ Si las cosas son un punto de vista particular de Dios, una concentración en perspectiva de todo lo demás, ${ }^{19}$ entonces, aunque por leyes de transformación Alguien pueda llegar al punto de vista universal, lo expresado permanece en cierto sentido oculto para lo expresante. En otros términos, la omnisciencia de lo finito, aunque marca de infinitud, es paradójicamente también lo que permanece oculto a su saber en el ámbito de lo oscuro y confuso. Este

15 Esto, como se dijo, refiere a su obra, pero no, claro está, a los sentimientos privados que pueda haber albergado el autor.

16 Es célebre el hecho de que fue Antoine Arnauld en su carta del 4 de marzo de 1687 quien pidió a Leibniz que le explicara qué entendía por el término 'expresión', lo que dio pie a una elucidación e intento de racionalización de dicho concepto por Leibniz. A II 2, 151. A= GoTTFRIED W. LeIBNIZ, Sämtliche Schriften und Briefe, hrsg. v. d. Preußischen (später: BerlinBrandenburgischen und Göttinger) Akademie der Wissenschaften zu Berlin, Darmstadt (später: Leipzig, zuletzt: Berlin), Akademie-Ausgabe. Desde 1923 y continúa. Se cita por serie, volumen y número de página.

17 A II 2, 426; A VI 4, 1618; A VI 4, 1624; GP IV, 562. GP= GotTfried W. LeIBNIZ, Die philosophischen Schriften, hrsg. v. C. I. Gerhardt, Berlin 1875-1890 (reimpr. Georg Olms Verlag, Hildesheim-New York 1978). Se cita por volumen y número de página.

18 Si bien no habla de ocultación, véase al respecto: OSCAR ESQUISABEL, « Perspectivism, Expression, and Logic in Leibniz. A Foundational Essay », Vorträge des X. Internationalen Leibniz-Kongresses, vol. III, Georg Olms Verlag, Hildesheim-Zürich-New York 2016, p. 73-87.

19 Para la mónada como 'mundo concentrado', el concepto de 'espejo viviente' y las imágenes usadas por Leibniz para ilustrarlo, véase: HeINRICH SCHEPERS, "Fiktion und Wahrheit », in ID., Leibniz. Wege zu seiner reifen Metaphysik, Akademie Verlag, Berlin 2014, p. 262-263. 
Griselda Gaiada

'perspectivismo perceptivo' de toda cosa finita se traduce en Leibniz por un sentimiento o percepción confusa de la totalidad, ${ }^{20}$ sentimiento del que quizá no sea aventurado decir que es en el hombre, tal como Borges lo vislumbró, la fuente de donde dimana la "inminencia de una revelación que no se produce ${ }^{21}$ el asomo del fondo que puja desde lo más recóndito del ser por entender o poder traducir lo que las cosas « dicen infinitamente ».

Es sabido que Leibniz pensó que toda cosa del mundo expresa a Dios, ya que en definitiva no es sino un punto de vista asumido por aquél. El símil de la ciudad, tantas veces por él evocado, es una de sus imágenes más elocuentes. ${ }^{22}$ Siguiendo el Discurso de metafísica, Paul Koehler lo explica como sigue: «porque al contemplar el sistema general de los fenómenos desde todos los aspectos posibles, el resultado de esta visión, en cuanto Dios decide hacer realidad lo que piensa, es una sustancia que expresa el universo según la visión divina $» .^{23}$ Este proceso, por así llamarlo, implica tanto dispersión como concentración; es a la vez dispersión de la unidad en la multiplicidad ${ }^{24}$ y concentración de la multiplicidad en cada unidad. Así cada cosa refleja todas las cosas, o es en cierto sentido todas las cosas; y también cada cosa refleja a Dios, o es en cierto sentido - que no implica identidad entre lo finito y lo infinito - Dios mismo bajo aspecto de limitación y de otredad. Leibniz dijo que las cosas «son como imágenes para Dios », ${ }^{25}$ Borges denunciará el reverso de tamaña tesis filosófica: acaso la dispersión no implicaría también que una imagen «se pierde para siempre en el caleidoscopio $"{ }^{26}$ que ya no volverá a ser lo que era para sí. El escritor argentino agrega: «perdimos esos rasgos, como puede perderse un número mágico, hecho de cifras habituales $»,{ }^{27}$ e inmediatamente después señala, no sin sus infaltables marcas de escepticismo: pero tal vez alguno de sus rasgos «acecha en cada

\footnotetext{
A II 2, 118; A II 2, 230-231; A II 2, 426; GP IV, 475; GP VII, 554-555; GP VI, 617.

Véase supra, nota 8.

2 A II 2, 19; A II 2, 91; A VI 4, 1542; GP IV, 554; GP VI, 616; GP VII, 567. Para una formulación temprana de la metáfora, véase: A VI 3, 524. Frente a interpretaciones que se verían tentadas de otorgar realidad a la ciudad más allá de sus observadores, o peor aún de asimilarla panteístamente a Dios, cabe destacar lo que explica Heinrich Schepers, apelando a una analogía con la informática: « la ciudad sólo está simulada, solamente son verdaderos los datos de la computadora que se precisan para generar la simulación. Sólo a través del pasaje de un conjunto de datos a otro sería posible visualizar los cambios; la simulación está, como se dice, animada ». SCHEPERS, « Fiktion und Wahrheit», p. 263. Salvo que se indique lo contrario, todas las citas de textos en lengua extranjera son traducción de la autora.

23 Paul Koenler, Der Begriff der Repräsentation bei Leibniz. Ein Beitrag zur Entstehungsgeschichte seines Systems, Bern 1913, p. 22. Véase también A VI 4, 1549-1550.

24 A VI 4, 1542; GP VII, 566-567.

25 A VI 3, 516.

26 Jorge LuIs Borges, « Paradiso, XXXI, 108 », El hacedor, O. C., p. 800.

27 Ibid.
} 
espejo », " tal vez la cara se borró para que Dios sea todos $»{ }^{28}$ Borges parece estar expresando en clave literaria una antigua tesis filosófica, de la que Leibniz a su manera también se hizo eco: algo se transforma y algo permanece en la dispersión, ${ }^{29}$ y no sólo eso, sino que lo que permanece es concentración. ${ }^{30} \mathrm{El}$ poema « Él » es uno de los más elocuentes al respecto:

Los ojos de tu carne ven el brillo

del insufrible sol, tu carne toca

polvo disperso o apretada roca;

Él es la luz, lo negro y lo amarillo.

Es y los ve. Desde incesantes ojos

te mira y es los ojos que un reflejo

indagan y los ojos del espejo,

las negras hidras y los tigres rojos.

No le basta crear. Es cada una

de las criaturas de Su extraño mundo:

las porfiadas raíces del profundo

cedro y las mutaciones de la luna.

Me llamaban Caín. Por mí el Eterno

sabe el sabor del fuego del infierno. ${ }^{31}$

Ibid.

29 Esta idea de permanencia es magistralmente expresada por Borges en « Nathaniel Hawthorne ». En su Earth's Holocaust, refiere el argentino, Hawthorne precisa un momento en que los hombres, hartos de acumulaciones inútiles, se resuelven a destruir el pasado. Con ese fin, se reúnen y encienden una altísima hoguera donde harán consumir todos los objetos que han llevado consigo. La parábola comporta un claro sentido filosófico, pero Hawthorne ha sido incapaz de verlo. El punto de la irremisible omisión denunciado por Borges es el siguiente: « si el mundo es el sueño de Alguien, si hay Alguien que ahora está soñándonos y que sueña la historia del universo, como es doctrina de la escuela idealista, la aniquilación de las religiones y de las artes, el incendio general de las bibliotecas, no importa mucho más que la destrucción de los muebles de un sueño. La mente que una vez los soñó volverá a soñarlos; mientras la mente siga soñando, nada se habrá perdido. La convicción de esta verdad, que parece fantástica, hizo que Schopenhauer, en su libro Parerga und Paralipomena, comparara la historia a un calidoscopio, en el que cambian las figuras, no los pedacitos de vidrio, a una eterna y confusa tragicomedia en la que cambian los papeles y máscaras, pero no los actores. Esa misma intuición de que el universo es una proyección de nuestra alma y de que la historia universal está en cada hombre, hizo escribir a Emerson el poema que se titula History» (BORGES, "Nathaniel Hawthorne ", p 679). Cabe agregar que el 'principio de Arlequín' en Leibniz, por llamarlo como lo hace Ortega y Gasset, es por su parte otra manera de referir al calidoscopio de Schopenhauer. Véase GotTfRied W. LeIBNIZ, Nouveaux essais sur l'entendement humain (Libro III, Cap. 6, § 39), A VI 6, 329.

30 Esto aparece también en el poema «Beppo»-nombre del gato de Borges en alusión a Lord Byron -: "Así lo afirma,/ sombra también, Plotino en las Enneadas./ ¿De qué Adán anterior al paraíso,/ de qué Divinidad indescifrable/ somos los hombres un espejo roto? » (JoRGE LUIS BORGES, « Beppo », La cifra, en Obras completas 1975-1985 [O. C.²], Emecé, Buenos Aires 1989, p. 297).

31 JORGE LUIS BORGES, « Él », El otro, el mismo, O. C., p. 898. Nuestro resaltado. 
Griselda Gaiada

Si los ojos de Dios se han multiplicado al infinito en la dispersión, Él es entonces los « ojos de la carne » y los ojos de las cosas, los « incesantes ojos » que indagan otros reflejos y los ojos de cada uno de esos reflejos; Él es, en suma, nos dice Borges, "cada una de las criaturas de su extraño mundo ». Lo es, pero no en cuanto lo mismo, sino en cuanto otro; no al parecer en cuanto mera distinción modal, como lo pretendía Spinoza, sino en cuanto genuina otredad de lo que permanece. No olvidemos que el tema de la alteridad y la mismidad ha sido uno de los tópicos mayores de la literatura borgeana y que incluso ha dado título a todo un volumen (El otro, el mismo, 1964). La 'exigencia metafísica' de otredad, limitación o, por así decirlo, 'finitización', a la que Borges alude en boca de Caín, remite en el fondo a uno de los misterios más insondables para el hombre, el porqué de la creación. ${ }^{32}$ La respuesta que el escritor aventura no declina en altura metafísica: « Por mí el Eterno sabe el sabor del fuego del infierno ». En tan sólo un verso, Borges nos abisma en la profundidad metafísica de toda una cosmogonía. Si lo finito en cuanto conectado con lo extenso implica sensación, sabor, deterioro, dolor, falta; Dios en cuanto conectado con lo finito no sabría ser enteramente ajeno a ello. ${ }^{33}$ Por el ser finito, pues, el Eterno prueba el sabor de la muerte y del infierno.

Ahora bien, si la expresión leibniziana supone una concentración de la totalidad en un punto nodal llamado 'sustancia', entonces 'todo está en todo'34 $\mathrm{y}$, por tanto, cada estado de un alma particular encierra todos sus estados precedentes y futuros, ${ }^{35}$ así como los del universo entero. "El presente está

32 Es frecuente en Borges la idea de que las cosas finitas son modos en los que Dios se manifiesta o revela a sí mismo por la alteridad, como por ejemplo en «De alguien a nadie »: «Las cosas particulares son teofanías y detrás está Dios que es el único real, pero que no sabe qué es, porque no es un qué, y es incomprensible a sí mismo y a toda inteligencia » (JoRGE LUIS BorGES, « De alguien a nadie, Otras inquisiciones, O.C., p. 738).

33 Véase GP VII, 411.

34 Este adagio es el nervio del emotivo elogio de Borges a Walt Whitman: «Plotino describe a sus alumnos un cielo inconcebible, en el que 'todo está en todas partes, cualquier cosa es todas las cosas, el sol es todas las estrellas, y cada estrella es todas las estrellas y el sol' (Enneadas, V, 8, 4) [...] Análogo, pero de voz más elemental, es Ich bin der Eine und bin Beide, de Stefan George (Der Stern des Bundes). Walt Whitman renovó ese procedimiento. No lo ejerció, como otros, para definir la divinidad o para jugar con las 'simpatías y diferencias' de las palabras; quiso identificarse, en una suerte de ternura feroz, con todos los hombres. [...] Walt Whitman, hombre, fue director del Brooklyn Eagle, y leyó sus ideas fundamentales en las páginas de Emerson, de Hegel y de Volney; Walt Whitman, personaje poético, las edujo del contacto de América, ilustrado por experiencias imaginarias en las alcobas de New Orleans y en los campos de batalla de Georgia. [...] Whitman deriva de su manejo una relación personal con cada futuro lector. Se confunde con él y dialoga con el otro, con Whitman [...] Así se desdobló en el Whitman eterno, en ese amigo que es un viejo poeta americano de mil ochocientos y tantos y también su leyenda y también cada uno de nosotros y también la felicidad. Vasta y casi inhumana fue la tarea, pero no fue menor la victoria » (BORGES, « Nota sobre Walt Whitman », p. 251-253).

35 A II 2, 123; A II 2, 171; A VI 4, 1551; A VI 4, 1571. 
grávido del porvenir - afirma Leibniz -, el futuro se podría leer en el pasado ${ }^{36} \mathrm{Y}$ añade: «toda alma conoce el infinito, conoce todo, aunque confusamente $»{ }^{37} \mathrm{La}$ omnisciencia de todo individuo, cualquiera sea su grado de consciencia, implica que cada uno de sus estados posee los datos suficientes para reconstruir el universo en su totalidad..$^{38}$ Así pues, un intelecto infinito podría leer el universo entero en los pétalos de una rosa. Borges, afecto a las posibilidades literarias de esta idea, especialmente por su conexión con el determinismo, la ha explotado no sólo como una poderosa ficción, sino tal vez como una de las ficciones humanas mejor fundadas. Así, en la irónica recensión del libro de M. Davidson, The Free Will Controversy, comienza recordando la omisión por parte del autor de la doctrina estoica, según la cual, «formando un todo el universo, cada una de sus partes prefigura (siquiera de un modo secreto) la historia de las otras $» .{ }^{39}$ De donde se sigue que si un mortal fuese capaz de « abarcar el encadenamiento general de las causas, sería infalible; pues el que conoce las causas de todos los acontecimientos futuros, prevé necesariamente el porvenir $\gg{ }^{40}$ Por si esto fuera poco, Borges da un paso más y adjudica al marqués de Laplace ${ }^{41}$ el hecho de haber jugado « con la posibilidad de cifrar en una sola fórmula matemática todos los hechos que componen un instante del mundo, para luego extraer de esa fórmula todo el porvenir y todo el pasado $\gg{ }^{42}$ Curiosamente, Borges remite aquí solamente a Laplace, pero la sospecha de una referencia tácita a Leibniz no sabría ser excluida. ¿Acaso la analogía leibniziana entre el despliegue de los estados de la sustancia y una serie infinita no es en esencia el cifrado aludido? ¿Acaso quien pudiese descubrir el término general de la serie no vería también que cada término de esa fórmula contiene todo el porvenir y todo el pasado del mundo?

\footnotetext{
GP VI, 604

Ibid.

A VI $4,1618$.

JoRge LuIs Borges, « M. Davidson, The Free Will Controversy (Watts, London, 1943) », Discusión, O. C., p. 282.

${ }^{41}$ Al respecto, véase PierRe Simon LAPLACE, Essai philosophique sur les probabilités, Bachelier, Paris 1840, p. 3-4. La pretendida deducción de Laplace se basa en un determinismo ontoepistemológico que debería constatarse no sólo en los cuerpos macroscópicos, sino también en las partículas elementales. Al destierro del 'demonio de Laplace' contribuirían sin duda los fenómenos cuánticos y el consecuente principio de incertidumbre de Heisenberg. Algunas lecturas recientes sostienen, no obstante, la indemnidad del engendro de Laplace ante el aparente comportamiento no determinista de los corpúsculos, por cuanto la experimentación a nuestro alcance o, mejor dicho, el estado actual de nuestra ciencia cuántica no alcanzaría para invalidar los cálculos de esa inteligencia omnisciente. Véase, por ejemplo, OLIVIER SARTENAER, « Pour mettre fin au mythe de Laplace », Revue de métaphysique et de morale, 94/2 (2017), p. 179200.

42 BORGES, « M. Davidson, The Free Will Controversy », p. 282-283. Nuestro resaltado.
}

40 Ibid. 
Griselda Gaiada

«El Zahir» es otro de los relatos donde Borges ahonda en la idea de la expresión universal, aunque esta vez llevándola hasta sus consecuencias más inauditas. Zahir significa en el pensamiento musulmán lo que es exterior, aparente, e incluso exotérico. La filosofía islámica lo opone al término batin, reservado para quienes pueden penetrar los misterios. El Zahir, en cambio, es cosa del vulgo, de aquéllos que, incapaces de penetrar en el interior de las cosas, no hacen sino contemplar la luz de Dios como se contempla el sol visible en el firmamento. Borges, por su parte, precisa el significado del término como sigue: « en árabe, quiere decir notorio, visible; en tal sentido, es uno de los noventa y nueve nombres de Dios $»{ }^{43}$ Nosotros, filosóficamente, diríamos que ese nombre representa a Dios bajo el atributo de la extensión. Pero Borges opera un giro magistral sobre la creencia islámica, por donde ingresa de golpe la faz inusitada de la doctrina de la expresión: la plebe, nos dice, lo aplica a las cosas cuya imagen inolvidable hace enloquecer a la gente. El Zahir es, pues, una superstición en tierras islámicas que refiere al poder que las cosas entrañan por ser imágenes del infinito. Un tigre, una serpiente, una flor, un guijarro pueden devenir el Zahir si, por su "terrible virtud de ser inolvidables $"{ }^{44}$ nos conducen a «la locura o la santidad $»{ }^{45}$ Para Borges, a la vez narrador y personaje del cuento, el Zahir fue una moneda vulgar de 20 centavos del año 1929. Haberla visto, realmente, en todo lo que muestra y oculta el metal, le comportó la terrible obsesión de ya no poder deshacerse de semejante visión: «el tiempo, que atenúa los recuerdos, agrava el del Zahir $»{ }^{46} \mathrm{El}$ paso de las noches no hizo sino avivar la visión inicial; ahora las caras de la moneda ya no se presentan en figuración sucesiva, sino de manera simultánea, « como si la visión fuese esférica y el Zahir campeara en su centro $»{ }^{47}$ Esa moneda del lejano sur, como cualquier otra cosa, lo expresa todo y, si pudiéramos abismarnos en su comprensión, su plenitud en latitud, longitud y altura nos revelaría el mundo y nos revelaría a Dios:

Dijo Tennyson que si pudiéramos comprender una sola flor sabríamos quiénes somos y qué es el mundo. Tal vez quiso decir que no hay hecho, por humilde que sea, que no implique la historia universal y su infinita concatenación de efectos y causas. Tal vez quiso decir que el mundo visible se da entero en cada representación, de igual manera que la voluntad, según Schopenhauer, se da entera en cada sujeto. Los cabalistas entendieron que el hombre es un microcosmo, un simbólico espejo del universo; todo, según Tennyson, lo sería. Todo, hasta el intolerable Zahir. ${ }^{48}$

Jorge LuIS Borges, « El Zahir », El Aleph, O. C., p. 593.

Ibid.

Ibid.

6 Ibid., p. 594.

47 Ibid.

48 Ibid., p. 594-595. 
«El Zahir - remata Borges - es la sombra de la Rosa y la rasgadura del Velo $»^{49} \mathrm{o}$, como lo insinuó el Apóstol, el oscuro espejo de la Rosa y la Rosa que aguarda detrás del espejo. Como de costumbre, Borges elude toda afirmación categórica, pero concluye la pavorosa verdad: "Quizá detrás de la moneda esté Dios ».50

Además de dispersión y concentración, la expresión, como nexo ontológico, implica también una conexión universal de cada cosa con todas las demás. " El universo - escribió Leibniz - es todo de una pieza, como un océano; el menor movimiento extiende su efecto a cualquier distancia, aunque ese efecto devenga menos sensible en proporción de la distancia $»{ }^{51}$ Del plenismo leibniziano se sigue que "toda la materia está ligada » y que " en el lleno todo movimiento produce algún efecto en los cuerpos distantes », es decir, que " esa comunicación llega a cualquier distancia $\wedge^{52} \mathrm{y}$, por tanto, es universal. En esta conexión de toda la materia en el pleno se funda el hecho de que el cuerpo exprese todo el universo $\mathrm{y}$, por el nexo representativo entre cuerpo y alma, que ésta también lo haga al representar el cuerpo que le pertenece. ${ }^{53}$ El universo es, pues, para Leibniz un " cierto " todo, no en el sentido de un todo mereológico, ${ }^{54}$ ni de una totalidad animada por una «Entelequia dominante ${ }^{55}$ porque en tal caso el mundo sería como un organismo o animal. Preocupado por evitar las implicancias de un Anima mundi y del panteísmo spinoziano, ${ }^{56}$ Leibniz vio en el nexo universal, que vincula expresivamente a todos los seres, lo que hace que el mundo se asemeje a un océano. Esta conexión tampoco supo, claro está, ser ajena a Borges, quien hace de ella un leitmotiv a lo largo de su obra. ${ }^{57}$ Aunque intercalando sus características

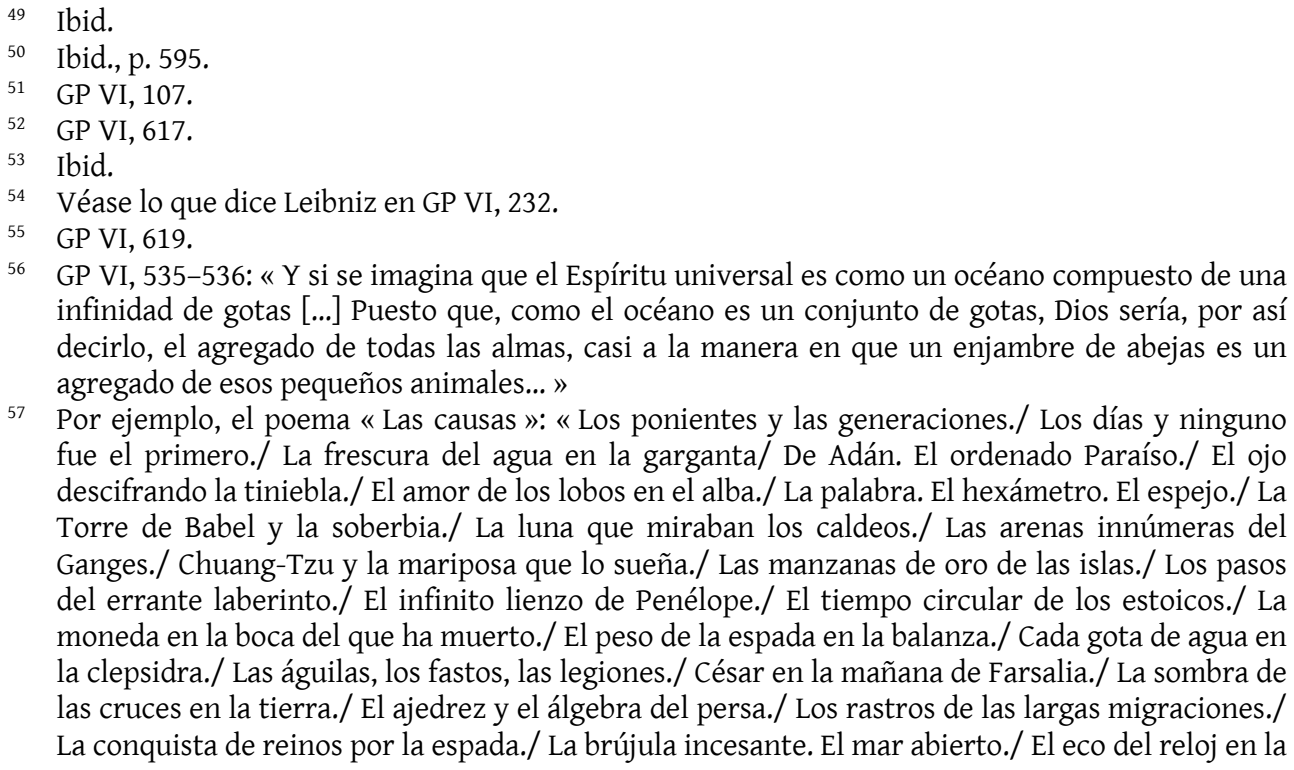

6 GP VI, 535-536: « Y si se imagina que el Espíritu universal es como un océano compuesto de una infinidad de gotas [...] Puesto que, como el océano es un conjunto de gotas, Dios sería, por así decirlo, el agregado de todas las almas, casi a la manera en que un enjambre de abejas es un agregado de esos pequeños animales...»

57 Por ejemplo, el poema «Las causas »: «Los ponientes y las generaciones./ Los días y ninguno fue el primero./ La frescura del agua en la garganta/ De Adán. El ordenado Paraíso./ El ojo descifrando la tiniebla./ El amor de los lobos en el alba./ La palabra. El hexámetro. El espejo./ La Torre de Babel y la soberbia./ La luna que miraban los caldeos./ Las arenas innúmeras del Ganges./ Chuang-Tzu y la mariposa que lo sueña./ Las manzanas de oro de las islas./ Los pasos del errante laberinto./ El infinito lienzo de Penélope./ El tiempo circular de los estoicos./ La moneda en la boca del que ha muerto./ El peso de la espada en la balanza./ Cada gota de agua en la clepsidra./ Las águilas, los fastos, las legiones./ César en la mañana de Farsalia./ La sombra de las cruces en la tierra./ El ajedrez y el álgebra del persa./ Los rastros de las largas migraciones./ La conquista de reinos por la espada./ La brújula incesante. El mar abierto./ El eco del reloj en la 
locuciones no asertivas, el escritor argentino también se aventura en la idea de que, tal vez, como lo pergeñó Leibniz, todo sea un "premeditado » acuerdo, unión, conspiratio (sympnoia panta). ${ }^{58}$ El poema "El bastón de laca» es probablemente una de las más bellas expresiones de ese vínculo que, inexorablemente, nos ataría:

Lo miro. Siento que es una parte de aquel imperio, infinito en el tiempo, que erigió su muralla para construir un recinto mágico.

Lo miro. Pienso en aquel Chuang Tzu que soñó que era una mariposa y que no sabía al despertar si era un hombre que había soñado ser una mariposa o una mariposa que ahora soñaba ser un hombre.

Lo miro. Pienso en el artesano que trabajó el bambú y lo dobló para que mi mano derecha pudiera calzar bien en el puño.

No sé si vive aún o si ha muerto.

No sé si es taoísta o budista o si interroga el libro de los sesenta y cuatro

hexagramas.

No nos veremos nunca.

Está perdido entre novecientos treinta millones.

Algo, sin embargo, nos ata.

No es imposible que Alguien haya premeditado este vínculo.

No es imposible que el universo necesite este vínculo. ${ }^{59}$

Ahora bien, hemos visto hasta el momento tres tesis fundamentales involucradas en el concepto de expresión: la cosmogonía implicada en la concentración por dispersión de la Unidad, la consecuente gravidez de pasado y porvenir en cada cosa, así como la conexión universal de todo con todo. Esta breve reflexión no podría concluirse sin presentar, aunque más no sea someramente, una última tesis relativa a la expresión, a saber, la de Dios, a la vez icnógrafo y escenógrafo. Es Leibniz quien, sirviéndose del lenguaje arquitectónico de Vitruvio, compara el punto de vista universal con una icnografía, ${ }^{60}$ es decir, con la visión de la planta entera de un edificio a partir de un plano que lo muestra cortado horizontalmente a ras del suelo, tal como lo vería un observador colocado

memoria./ El rey ajusticiado por el hacha./ El polvo incalculable que fue ejércitos./ La voz del ruiseñor en Dinamarca./ La escrupulosa línea del calígrafo./ El rostro del suicida en el espejo./ El naipe del tahúr. El oro ávido./ Las formas de la nube en el desierto./ Cada arabesco del calidoscopio./ Cada remordimiento y cada lágrima./ Se precisaron todas esas cosas/ Para que nuestras manos se encontraran » (JORGE LUIS BORGES, "Las causas », Historia de la noche, en Obra poética 1923-1977, Alianza-Emecé, Buenos Aires 1981, p. 552-553).

58 Couturat, 14-15; A VI 4, 1618; A VI 6, 55; GP VI, 617. Couturat = GotTFRIED W. LeIBNIZ, Opuscules et fragments inédits de Leibniz. Extraits de Manuscrits de la Bibliothèque Royale de Hanovre, édités par Louis Couturat, Félix Alcan éditeur, Paris 1903.

59 JORGE LUIS BORGES, «El bastón de laca », La cifra, O. C. ${ }^{2}$, p. 330. Nuestro resaltado.

60 Del griego, ikhnos, « traza ». Ichnografía pues por analogía con la visión de una huella dejada en tierra por el hombre. 
perpendicularmente sobre él. El punto de vista particular lo asocia, en cambio, con la representación en perspectiva del edificio, es decir, con una escenografía. ${ }^{61}$ «Una icnografía - afirma Leibniz - tiene infinitas escenografías ». ${ }^{62}$ Dicho de modo análogo, los puntos de vista particulares son al punto de vista universal, lo que las escenografías a la icnografía. La analogía echa luz sobre un aspecto central, ya sugerido supra, que atañe a la constitución ontológica de toda cosa finita: el individuo es una concentración del mundo, ${ }^{63}$ una cierta perspectiva de éste, parcial, según la visión asumida por Dios. ${ }^{64} \mathrm{Si}$ cada cosa es en cierto modo todas las cosas, o mejor dicho, es el mundo expuesto de modo parcial, y por así decir como anamórficamente 'deformado', entonces todo ser es una concentración perspectivista de todo lo demás, incluido Dios. Y como tal, se diferencia del punto de vista universal, entendido como concentración panóptica del mundo, esto es, del punto de vista definitivo y absoluto: Dios. ${ }^{65}$

Pronto se ve que esta idea constituye por su fecundidad un recurso formidable para la imaginación literaria, un manantial en curso para la realización de sus posibilidades poéticas o narrativas. La metafísica de un Dios visto como concentración de todos los puntos de visión en un único punto omnicomprensivo de todo otro, no sólo deviene 'fantástica', sino también ocasión de encuentro para que literatura y metafísica traben, por su parte, una relación especular. Borges parece haberlo comprendido así, pues su famoso cuento « El Aleph » se nos revela como una extraordinaria realización narrativa de esa inconcebible divinidad panóptica que Leibniz habría defendido. No viene al caso mencionar aquí las implicancias del título elegido por Borges para el pensamiento hebreo y los cabalistas en general. ${ }^{66}$ Nos conformaremos tan sólo con recordar brevemente la trama que él urdió para conducirnos a su fabulosa visión del Aleph.

El cuento comienza con la muerte de Beatriz Viterbo, amor no correspondido de Borges. Cada año, en la fecha de su cumpleaños, el escritor honraba su memoria visitando la casa donde Beatriz había vivido junto a su primo hermano y

61 Del latín, scaenographia, es decir, « corte en perspectiva ».

62 A VI 4, 1618. Además GP II, 438. Al respecto, véase SCHEPERS, « Fiktion und Wahrheit », p. 263, así como su conferencia «Iter rationis. Reise der Vernunft in Leibniz' Welt der Monaden », Studia Leibnitiana, 49/1 (2017), p. 12.

63 GP IV, 542; GP IV, 553; GP VII, 411; A VI 4, 2237.

64 Véase EsquiSABEL, "Perspectivism, Expression, and Logic in Leibniz », p. 75.

65 GP VII, 556.

66 Al respecto, cabe destacar la conferencia de Borges, titulada «La cábala » (26 de julio de 1977, Teatro Coliseo de Buenos Aires), cuya versión revisada fue publicada junto a las demás conferencias del ciclo bajo el título de Siete noches. Véase JORGE LUIS BORGES, «La cábala », Siete noches, O. C. ${ }^{2}$, p. 267-275. Para un análisis del significado de la letra hebrea Aleph en este cuento de Borges a la luz de la cábala y del Talmud, véase: CLAUDE VigéE, «Borges devant la Kaballe juive. De l'écriture de Dieu au silence de l'Aleph », Revue de littérature comparée, 320/4 (2006), p. 397-413. 
amante, Carlos Argentino Daneri ${ }^{67}$. Las extravagancias de éste último no eran menores, como tampoco lo era la intolerancia que provocaban en Borges. Entre las excentricidades de Daneri, figuraba el hecho de que pergeñaba escribir un poema, «La Tierra », cuyo propósito (o despropósito) no era otro que la tarea de versificar cada hecho contenido en el orbe. Tamaña ocurrencia pareció a Borges de un pedantismo sin precedentes, agravado por el amateurismo poético de Daneri. Temeroso de que éste le pidiese prologar su «pedantesco fárrago $"{ }^{68}$ decidió apartarse de su trato. Pasado el tiempo, sin embargo, un día sonó el teléfono de su casa. Borges escuchó entonces la voz del primo de su amada, una "voz llana, impersonal », ${ }^{69}$ que trasmitía la urgencia de querer confiarle algo muy íntimo. En efecto, Daneri lo llamaba para comunicarle que sus vecinos albergaban la monstruosa intención de demoler su casa. Su desconsuelo no tenía parangón. El motivo de ello era que «para terminar el poema le era indispensable la casa $"{ }^{70}$ indispensable, porque en un ángulo de su sótano había un Aleph. Le explicó entonces que un Aleph es « uno de los puntos del espacio que contiene todos los puntos ", ${ }^{71}$ y añadió que, tempranamente, le había sido dada la comprensión de que ese sótano alojaba todo un mundo para que, llegado el momento, « el hombre burilara el poema ». ${ }^{72}$ Allí se escondía, confesó a Borges, " el lugar donde están, sin confundirse, todos los lugares del orbe, vistos desde todos los ángulos ${ }^{73}{ }^{73}$ Pasmado por lo inconcebible de esta revelación, Borges se precipitó a casa de Daneri. Una vez allí, éste lo incitó, o más bien lo provocó, a probar su sótano, no sin antes convidarlo con una bebida espirituosa y hacerle las debidas recomendaciones del caso, entre las cuales, cierta posición del cuerpo y « cierta acomodación ocular ». ${ }^{74}$ Sólo así, le dijo, podría ver el multum in parvo de cabalistas y de alquimistas en trance.

Es aquí en realidad cuando comienza stricto sensu el relato, o más bien el « inefable centro $»^{75}$ del relato borgeano que trasunta su «desesperación de escritor ». « ¿Cómo - se pregunta Borges - transmitir a los otros el infinito Aleph que mi temerosa memoria apenas abarca? $\gg^{76} \mathrm{El}$ problema al que se enfrenta es, naturalmente, irresoluble. Ni el más virtuoso filigranista de la escritura podría

67 Véase la interpretación que ofrece Vigée de este personaje a partir del nombre ideado por Borges, especialmente lo que refiere a la composición del apellido Daneri, en VIGÉE, « Borges devant la Kaballe juive », p. 398.

68 Jorge Luis Borges, « El Aleph », El Aleph, O. C., p. 621.

69 IbId., p. 623.

Ibid.

Ibid.

Ibid.

Ibid.

Ibid., p. 624.

Ibid.

Ibid. 
acometerlo, por la sencilla razón de que su trama se compone de letras de algún alfabeto, de cifras, de símbolos, que son numerables. Por ende, el lenguaje no puede sino ocultar en lo que refleja, alude y a duras penas enumera, la experiencia, aterradora, del infinito. Pero dejemos que sea Borges quien concluya nuestro periplo con su visión del Aleph, que quizá haya sido también la del Dios de Leibniz, o su soñado reflejo:

En ese instante gigantesco, he visto millones de actos deleitables o atroces; ninguno me asombró como el hecho de que todos ocuparan el mismo punto, sin superposición y sin trasparencia. Lo que vieron mis ojos fue simultáneo: lo que transcribiré, sucesivo, porque el lenguaje lo es. Algo, sin embargo, recogeré.

En la parte inferior del escalón, hacia la derecha, vi una pequeña esfera tornasolada, de casi intolerable fulgor. Al principio la creí giratoria; luego comprendí que ese movimiento era una ilusión producida por los vertiginosos espectáculos que encerraba. El diámetro del Aleph sería de dos o tres centímetros, pero el espacio cósmico estaba ahí, sin disminución de tamaño. Cada cosa (la luna del espejo, digamos) era infinitas cosas, porque yo claramente la veía desde todos los puntos del universo. Vi el populoso mar, vi el alba y la tarde, vi las muchedumbres de América, vi una plateada telaraña en el centro de una negra pirámide, vi un laberinto roto (era Londres), vi interminables ojos inmediatos escrutándose en mí como en un espejo, vi todos los espejos del planeta y ninguno me reflejó, (...) vi en un gabinete de Alkmaar un globo terráqueo entre dos espejos que lo multiplican sin fin, (...) vi la reliquia atroz de lo que deliciosamente había sido Beatriz Viterbo, vi la circulación de mi oscura sangre, vi el engranaje del amor y la modificación de la muerte, vi el Aleph, desde todos los puntos, vi en el Aleph la tierra, y en la tierra otra vez el Aleph y en el Aleph la tierra, vi mi cara y mis vísceras, vi tu cara, y sentí vértigo y lloré, porque mis ojos habian visto ese objeto secreto y conjetural, cuyo nombre usurpan los hombres, pero que ningún hombre ha mirado: el inconcebible universo. ${ }^{77}$

Hemos comenzado este escrito con la 'definición' de la metafísica dada por Borges. Su desembozada ironía podría inducirnos precipitadamente a juzgarla como una desafiante declaración 'anti-tradicionalista'. En efecto, a una larga tradición que ha visto en la metafísica no sólo una ciencia, la de los primeros principios, sino también su primacía por sobre toda otra forma de conocimiento, Borges opuso irreverentemente su concepción de la metafísica como una rama de la literatura fantástica, ergo como un producto de la imaginación humana. Una interpretación literal de sus palabras no iría más allá del plano manifiesto de la invalidación de esa pretendida ciencia, cuyo descrédito quedaría sentado en el

77 Ibid., p. 625-626. Nuestro resaltado. 
Griselda Gaiada

acto mismo en que las 'verdades metafísicas' son rebajadas a una simple creación del hombre. No obstante, una segunda lectura, que se permitiera ir más lejos, podría avanzar hacia el fondo de verdad velado por lo dicho. ¿Acaso no es cierto que cualquier doctrina o filosofía que tome por objeto a Dios, al fundamento de la realidad visible, a lo que se rebela a la conceptualización humana, no es en el fondo una representación parcial que depende más de un acto de fe que de los conceptos que moviliza? ¿Acaso la metafísica, en su reinvención constante, no es un relato más próximo a la literatura que a la ciencia?

Borges parece decirnos que todo sistema metafísico se funda a fin de cuentas en creencias que los conceptos buscan justificar, siendo en el fondo incapaz de producir un asentimiento mayor que el atribuible a una narración fantástica o, mejor dicho, siendo igualmente capaz de suscitar sorpresa, inquietud, duda, incomprensión. En ambos casos la fisura está allí, dislocando la auto-justificación del sistema, introduciendo lo inexplicable en el relato. A decir verdad, dicha apreciación borgeana no hace más que destacar un hecho harto evidente: el lenguaje se inscribe en un orden humano $y$, cuando sus producciones tienen que ver con un orden que lo excede, sólo son juzgables por los sentimientos que suscitan en razón de aquello que evocan, aluden, sugieren, sin jamás traerlo enteramente. Para Borges, la metafísica y la poesía son sus mejores ejemplos. Una y otra expresan una realidad que está allí sin dejarse aprehender. o lo que es igual, lo que exteriorizan ambas oculta a la vez una infinidad de cosas, al igual que cualquier existencia del mundo. El concepto leibniziano de expresión parece, pues, ocupar el centro de las inquietudes borgeanas. Más aún, como hemos visto, el escritor ha dado forma literaria a las principales tesis metafísicas que comporta el concepto de expresión: dispersión, concentración, conexión universal, puntos de vista individual y universal. Y no sólo ello, sino que además es dable afirmar, sin miedo a error, que no existe pluma que mejor haya plasmado las posibilidades literarias de esta 'metafísica de los espejos'. Las afinidades entre Borges y Leibniz son asombrosas, la determinación de su ámbito de influencia, no obstante, oscura. Tributario directo de la figura de Leibniz o quizá parte de una inmemorial tradición común, Borges se nos muestra - no fue otro nuestro cometido - unido a Leibniz en secreta conspiratio. No es imposible, concluimos, que Alguien haya premeditado este vínculo. No es imposible, una vez más, que el universo necesite este vínculo. 


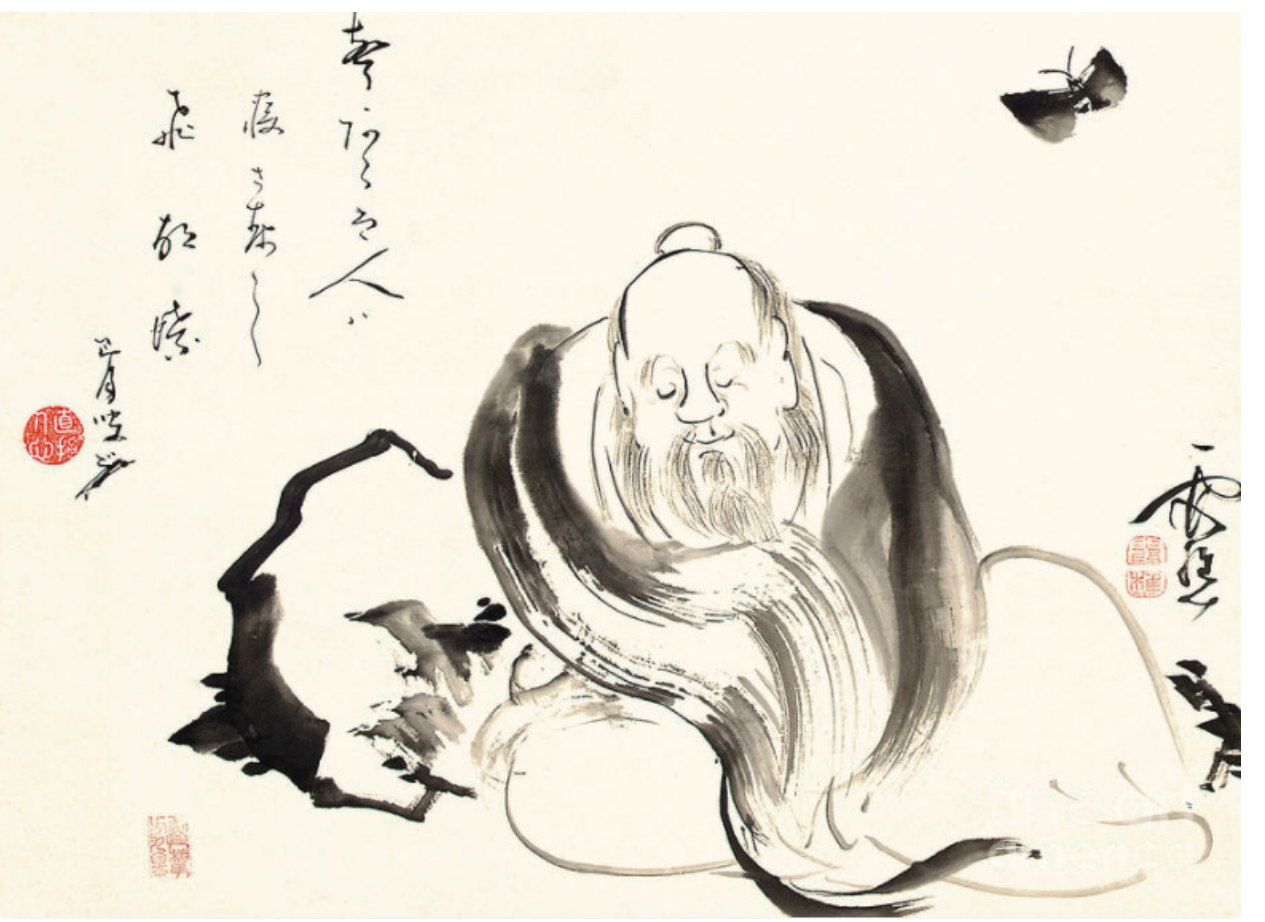

Fig. 1. El sueño de la mariposa, Ike no Taiga (1723-1776) 
Griselda Gaiada

\section{Bibliografía}

Aizenberg, Edna, The Aleph Weaver: Biblical, Kabbalistic and Judaic Elements in Borges, Scripta Humanistica, Potomac (Maryland) 1984.

Alazraki, Jaime, Borges and the Kabbalah, and Other Essays on His Fiction and Poetry, Cambridge University Press, Cambridge 1988.

Block de Behar, Lisa, The Passion of an Endless Quotation, trans. William Egginton, State University of New York Press, New York 2003.

Borges, Jorge Luis, Obras completas 1923-1972, Emecé, Buenos Aires 1974.

- Obras completas 1975-1985, Emecé, Buenos Aires 1989.

- « Notas bibliográficas », in Laura Rosato, Germán Álvarez (eds.), Borges, libros y lecturas. Catálogo de la colección Jorge Luis Borges en la Biblioteca Nacional, Biblioteca Nacional, Buenos Aires 2010.

Borges, Jorge Luis, Ernesto Sabato, Diálogos, Emecé, Buenos Aires 1976.

Castany Prado, Bernat, Que nada se sabe: el escepticismo en la obra de Jorge Luis Borges, Cuadernos de América sin nombre $\mathrm{N}^{\circ}$ 31, Universidad de Alicante 2012.

Devran, Albert, Borges et la Kabbale, Edition Géranium, Bruselas 1967.

Esquisabel, Oscar, "Perspectivism, Expression, and Logic in Leibniz. A Foundational Essay », Vorträge des X. Internationalen Leibniz-Kongresses (Band III), Georg Olms Verlag, Hildesheim-Zürich-New York 2016, p. 73-87.

Goldenbaum, Ursula, «La fascinación de Leibniz por Spinoza», in Leticia Cabañas, Oscar Esquisabel (eds.), Leibniz frente a Spinoza, Comares, Granada 2014, p. 31-50.

Jaén, Didier T., Borges' Esoteric Library: Metaphysics to Metafiction, University Press of America, Lanham 1992.

Kazmierczak, Marcin, «La metafísica idealista en los relatos de Jorge Luis Borges », tesis doctoral, Universidad Autónoma de Barcelona 2001.

Koehler, Paul, Der Begriff der Repräsentation bei Leibniz. Ein Beitrag zur Entstehungsgeschichte seines Systems, Dissertation, Rheinische Friedrich-WilhelmsUniversität Bonn, Bern 1913.

Laplace, Pierre Simon, Essai philosophique sur les probabilités, Bachelier, Paris 1840.

Leibniz, Gottfried Wilhelm, Die philosophischen Schriften, hrsg. v. C. I. Gerhardt, Berlin, 1875-1890 (reimpr. Georg Olms Verlag, Hildesheim-New York, 1978). Se cita por volumen y número de página. 
Leibniz, Gottfried Wilhelm, Opuscules et fragments inédits de Leibniz. Extraits de Manuscrits de la Bibliothèque Royale de Hanovre, édités par Louis Couturat, Félix Alcan éditeur, Paris 1903. Se cita como Couturat, seguido del número de página.

Leibniz, Gottfried Wilhelm, Sämtliche Schriften und Briefe, hrsg. v. d. Preußischen (später: Berlin-Brandenburgischen und Göttinger) Akademie der Wissenschaften zu Berlin, Darmstadt (später: Leipzig, zuletzt: Berlin), Akademie-Ausgabe. Desde 1923 y continúa. Se cita por serie, volumen y número de página.

Nuño, Juan, La filosofía en Borges, Reverso Ediciones, Barcelona 2005.

Sartenaer, Olivier, "Pour mettre fin au mythe de Laplace », Revue de métaphysique et de morale, 94 (2017/2), p. 179-200.

Sasso, Marcelo, Borges en clave de Elea, Teseo Press, Buenos Aires 2015.

Schepers, Heinrich, "Iter rationis. Reise der Vernunft in Leibniz' Welt der Monaden », Studia Leibnitiana, 49 (2017/1), p. 2-27.

- Wege zu seiner reifen Metaphysik, Akademie Verlag, Berlin 2014.

Sosnowski, Saúl, «Borges y la Cábala: La búsqueda del Verbo », Nuevos Aires, 8 (1972), p. 39-48.

Vigée, Claude, «Borges devant la Kaballe juive. De l'écriture de Dieu au silence de l'Aleph », Revue de littérature comparée, 320 (2006/4), p. 397-413.

Wolfson, Elliot, "In the Mirror of the Dream: Borges and the Poetics of Kabbalah », The Jewish Quarterly Review, 104 (2014/3), p. 362-379. 